\title{
THE STRENGTH OF SNOW IN COMPRESSION*
}

\author{
By LORNe W. Gold \\ (Snow and Ice Section, Division of Building Research, National Research Council, Canada)
}

\begin{abstract}
The hardness observations taken in the Canadian Snow Survey are analysed and found to depend on snow density, temperature, and crystal size. This strength property of the snow is found to be highly variable and the variability is attributed to unstable bonding between individual snow grains.

Zusammenfassung. Die Auswertung von Härtebeobachtungen, die während der zur Zeit in Kanada seitens der Regierung ausgeführten Schneeruntersuchungsarbeiten gemacht wurden, zeigt, dass die Härte von der Dichte, der Temperatur und der Kristallgrösse abhängt. Diese Festigkeitseigenschaft des Schnees hat sich dabei als stark veränderlich erwiesen, und die Veränderlichkeit ist labiler Bindung zwischen einzelnen Schneekörnern zuzuschreiben.
\end{abstract}

\section{INTRODUCTION}

During the past few years fairly extensive studies have been made on the mechanical strength of snow under conditions that cause the structure to deform very slowly with time. These studies have been successful in problems where the snow is acted upon by the natural forces associated with gravity and temperature 1 . More recently, attention has been directed to the behaviour of snow under applied loads such as those imposed by a ski or track ${ }^{2}$. The behaviour of the snow under the two conditions of loading is quite different. In the first case the deformation process over the range of measurement is continuous while in the second case the applied loads cause structural collapse resulting in a discontinuous deformation process. In both cases, the critical stress at which a discontinuity occurs in the deformation is of prime importance.

During its formation in the air a snow particle develops a shape determined by its internal crystalline structure and the properties of the air in which it grows. Each particle has a basic hexagonal symmetry and may be dendritic, plate-like or columnar in shape ${ }^{3}$. Once it is deposited on the ground, thermodynamic instability supports a decay and growth process which modifies the snow particles causing them to lose their characteristic crystalline development and tend to a common granular shape 4,5 . Bonds are developed between the grains which give to the snow cover its strength and rigidity. As the decay and growth process continues bonds are destroyed, the snow settles causing more intimate contact between grains and new bonds develop.

During its early history the behaviour of the snow under applied loads is determined primarily by the nature of the bonds between the grains. If the strength of the bonds is exceeded the snow structure will collapse resulting in a sudden increase in the density. As the snow settles, the density approaches a maximum value. When the snow is in this state the strength properties of the grains and the boundary conditions associated with the loading play a significant role in determining the behaviour of the snow.

As the snow cover is modified with time, it would be expected that certain properties of the snow would, on the average, be related to this modification. This would certainly be true of those strength properties which depend on the nature of the interaction between grains. Because this interaction, particularly the bonding, is sensitive to the thermodynamic conditions of the environment, these strength properties are potentially capable of a wide variation for any snow. If sufficient data are available, an average dependence of these strength properties on measurable descriptive properties of the snow can be established. If the scatter of the data about a mean value is large, the value of such relationships is limited as far as individual readings are concerned. The indefinite nature of such information, even if a mean value is well defined, is emphasized here and should

* This paper is a contribution from the Division of Building Research, National Research Council, Canada, and is published with the approval of the Director. 
be kept in mind while reading this paper. Only when the variance associated with the mean has a reasonably small value can relationships be put on an exact basis in the sense that, from a knowledge of certain descriptive properties, one can estimate the strength properties with a useful degree of accuracy.

The following discussion deals with the average relationships that exist between one of the strength properties of snow (its ultimate strength in compression as measured by the Snow Hardness Gauge, National Research Council type) and the density, temperature and grain size of the snow.

\section{SNOW HARDNESS}

In the snow survey which has been conducted in Canada since $1947^{6}$, one of the measurements taken involves the strength properties of the snow and is given the name "snow hardness". For this observation, a circular plate is pressed against a flat vertical face of the snow cover by means of a spring-loaded rod $^{7}$. At some stress, as measured by a scale associated with the spring, the snow under the plate collapses, allowing the plate to penetrate a fraction of an inch into the snow. The stress at which this penetration occurs is recorded as the "hardness" number.

It might be thought that this hardness number involves some combination of the ultimate strength of snow in compression and shear. To see if this were so, a number of observations were made with the snow cut by a knife normal to the bearing plate and around its circumference in such a way as to eliminate the contribution to the hardness number of shear stresses at the edge. It was found that this did not significantly change the hardness number measured.

A series of observations was also made with an apparatus that recorded, as a function of penetration, the force necessary to push a circular plate continuously into the snow. Fig. I (p. 72I) shows typical curves obtained. The rate of penetration was approximately one foot $(0.30 \mathrm{~m}$. $)$ per second. It will be noted that the stress attains quite a well defined value before penetration begins. Thereafter the rate of increase of stress with penetration is greatly reduced.

When properly used the Snow Hardness Gauge N.R.C. type measures the maximum stress associated with the initial collapse of the snow structure under a compressive load. This fact, coupled with the negligible effect of the shear stresses acting at the circumference of the plate indicates that the "hardness" number recorded in the survey is a reasonable measure of the ultimate strength of snow in compression. From the data accumulated it was possible therefore to show how an average value of the strength of snow in compression depends on the density, temperature, and crystal size of the snow. The data on which the analysis was made were collected at Resolute and Aklavik, N.W.T.; Whitehorse, Yukon; Edmonton and Old Glory, Alberta; Winnipeg and Churchill, Manitoba; Toronto, Ottawa, Moosonee, Gogama and Kapuskasing, Ontario; Maniwaki, Shawbridge, Shipshaw and Forestville, Quebec; Gander, Newfoundland; Goose Bay, Labrador, and Fredericton, New Brunswick. (Fig. 2, p. 721.)

\section{ANalysis of Data}

The scale of the Snow Hardness Gauge, N.R.C. type has eleven divisions numbered $\circ$ to ro. The number indicated by the gauge when the snow first fails is multiplied by a scale factor of I, 10, 100, or 1000, depending on the area of the plate used, to give the hardness in $\mathrm{gm} . / \mathrm{cm} .{ }^{2}$. This fact was used in grouping the data. For example, all points lying in the range 45 to 54 were grouped and given the value 50 , all points in the range 651 to 749 were given the value 700 etc. Those readings at $45,55,650,75^{\circ}$ etc. were divided evenly between the two adjacent groups. Furthermore, all readings involving crystals of size larger than $\mathrm{I} \mathrm{mm}$. with gauge plates of area less than I0 $\mathrm{cm} .{ }^{2}$ were neglected. Approximately 2000 observations were available for analysis. 

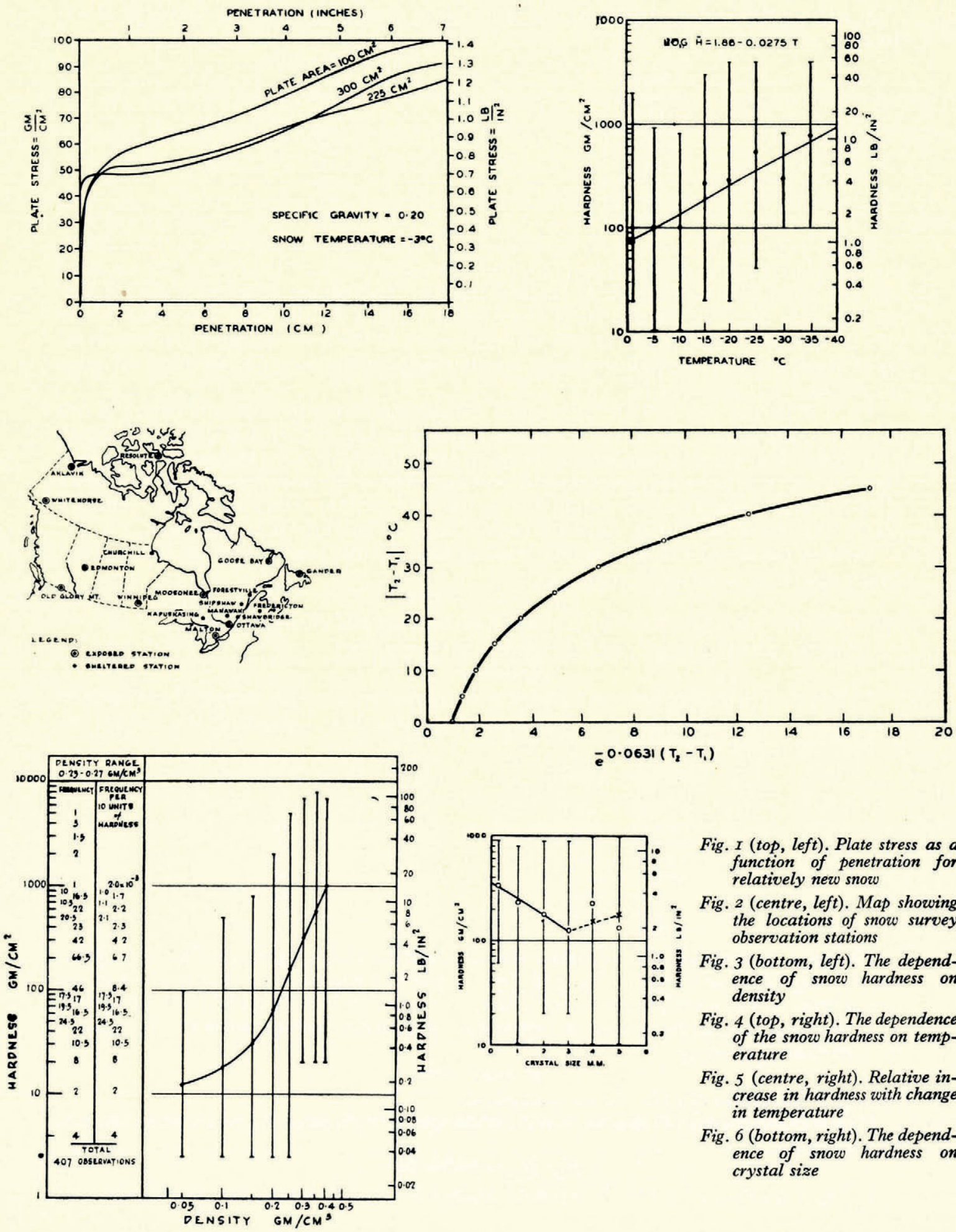

Fig. I (top, left). Plate stress as a function of penetration for relatively new snow

Fig. 2 (centre, left). Map showing the locations of snow survey observation stations

Fig. 3 (bottom, left). The dependence of snow hardness on density

Fig. 4 (top, right). The dependence of the snow hardness on temperature

Fig. 5 (centre, right). Relative increase in hardness with change in temperature

Fig. 6 (bottom, right). The dependence of snow hardness on crystal size 
In relating the hardness to density, the observations were grouped into the following density classes :

Density Class
$\left(\mathrm{gm} . / \mathrm{cm} .3^{3}\right)$
$0.05-0.07$
$0.08-0.12$
$0.13-0.17$
$0.18-0.22$
$0.23-0.27$
$0.28-0.32$
$0.33-0.37$
$0.38-0.42$

No. of Observations

In Fig. 3 (p. 72I) the mean of the logarithms of the hardnesses was calculated for each density class and plotted against the logarithm of the mean density of the class. The vertical line associated with each point gives the range in the hardness readings. The column of figures on the left illustrates in more detail the distribution of observations within a density class. The outer column gives the number of observations in each hardness class and the inner column the average number of observations corresponding to each ten unit range in hardness (i.e. for hardness range I $60 \mathrm{gm} . / \mathrm{cm} .^{2}$ to $\left.170 \mathrm{gm} . / \mathrm{cm}^{2}\right)$.

Fig. 3 illustrates very well the point raised initially concerning the indefinite nature of data that have a large spread. The spread in hardness readings for each density class is immense though a remarkably well defined dependence of the mean of the logarithm of the hardnesses on the density is present. One interesting point observed was that a plot of the mean logarithm of the median of the hardness readings for each density class against the logarithm of the mean density coincided exactly with that shown in Fig. 3 over the density range $0.2 \mathrm{gm} . / \mathrm{cm} .^{3}$ to $0.4 \mathrm{gm} . / \mathrm{cm} .{ }^{3}$.

Between the densities of $0.2 \mathrm{gm} . / \mathrm{cm} .{ }^{3}$ and $0.4 \mathrm{gm} . / \mathrm{cm} .{ }^{3}$ the relation between hardness and density can be expressed by the equation:

$$
\bar{H}=3.55 \times 10^{4} \bar{\rho}^{3.92},
$$

where $\bar{H}$ is the hardness defined by the mean logarithm and $\bar{\rho}$ is the mean density.

Below the density $0.15 \mathrm{gm} . / \mathrm{cm} .{ }^{3}$ the relationship is given by:

$$
\bar{H}=6 \cdot 67 \mathrm{e}^{10 \cdot 24 \bar{\rho}}
$$

To find the relationship between hardness and temperature, a random sample of 208 hardness readings and associated temperatures was obtained from the data. This sample was divided into

\begin{tabular}{|c|c|c|}
\hline Temperature & Class & No. of Obse \\
\hline$\circ$ to & $-2 \cdot 4$ & \\
\hline-2.5 to & $-7 \cdot 4$ & \\
\hline-7.5 to & $-12 \cdot 4$ & \\
\hline $\begin{array}{l}-12.5 \text { to } \\
-17.5 \text { to }\end{array}$ & $\begin{array}{l}-17.4 \\
-22.4\end{array}$ & \\
\hline-22.5 to & $-27 \cdot 4$ & \\
\hline-27.5 to - & $-32 \cdot 4$ & \\
\hline-32.5 to - & -37 & \\
\hline
\end{tabular}
the following temperature classes:

The mean logarithm of the hardnesses was calculated for each temperature class and plotted against temperature as shown in Fig. 4 (p. 72r). Again, the spread in the data is given by the vertical lines. The best straight line to fit the points was calculated by the method of least squares.

It was found that the dependence on temperature of the mean hardness defined by the mean of the logarithms is given by:

$$
\bar{H}=72 \mathrm{e}^{-0.063 T}
$$

where $T$ is the temperature in degrees Centigrade.

If snow at temperature $T_{1}$ and hardness $H_{1}$ is changed to temperature $T_{2}$, the resulting hardness $\mathrm{H}_{2}$ is given by:

$$
H_{2}=H_{1} \mathrm{e}^{-0.063\left(T_{2}-T_{1}\right)}
$$

In Fig. 5 (p. $72 \mathrm{r}$ ), $\mathrm{e}^{-0.063\left(T_{2}-T_{1}\right)}$ is plotted against $T_{2}-T_{1}$. It is seen that the hardness in- 
creases by a factor of $1 \cdot 9$ for each $10^{\circ} \mathrm{C}$. drop in temperature. It is unreasonable to expect that this would continue indefinitely. It is probable that the results are applicable only over a restricted temperature range.

This increase in the strength of snow with decrease in temperature may not be due alone to the significant increase in the strength of ice with decrease in temperature near $0^{\circ} \mathrm{C} .{ }^{8}$. The snow tested in each case had some opportunity to arrive at a state of thermodynamic equilibrium. As the temperature decreases, water vapour present in the voids of the snow will freeze out, thus tending to increase the bonding between particles and therefore increase the strength of the snow. The increase in strength of the snow due to freezing-out of vapour would be most significant in the temperature range $0^{\circ}$ to $-40^{\circ} \mathrm{C}$. since it is throughout this range that the variation with temperature of the amount of vapour in equilibrium with an ice surface is appreciable.

To test for a relationship between hardness and crystal size, a random sample of 207 observations was taken from the data. The measurements were taken in snow at least $20 \mathrm{~cm}$. below the surface during the winter months when the mean air temperature was significantly below $0^{\circ} \mathrm{C}$. New snow and snow conditioned by fall and spring climatic variations were therefore not included. Depth hoar and similar type crystals were also omitted. The reason for this choice is that new snow and depth hoar are not geometrically in the same class as settling or settled snow. Snow subjected to melting temperatures appears to have different hardness characteristics from snow which has existed continuously at below-freezing temperatures.

The observations were grouped into the following classes according to crystal size.

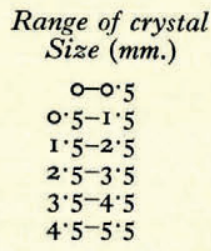

No. of Observations
\[ \]
8
67
64
41
14
13

The mean logarithm of the hardness was calculated for each class interval and plotted against the mean diameter of the class as shown in Fig. 6 (p. 72I). The vertical line associated with each point gives the spread in the hardness observations with each class.

It was considered that there were not enough observations over the range $3.5 \mathrm{~mm}$. to $5.5 \mathrm{~mm}$. to establish a valid mean so a new mean was calculated using all observations available in this size range (including spring snow but not new snow or depth hoar). The resulting values are designated in Fig. 6 by " $X$ " and the line that they define together with the mean logarithm of the hardness for $3 \mathrm{~mm}$. is indicated by a dashed line.

The dependence of the mean logarithm of the hardness on crystal size is poorly defined by the original data chosen for sizes greater than $3 \mathrm{~mm}$. but on the second choice of data for the larger crystal sizes a dependence is present. This dependence exhibits a trend opposite to that shown by the smaller crystal sizes. The reason for this may be the increase in density and, therefore, hardness, which is normally associated with snow the crystals of which are developing into this size range. These sizes normally develop in the snow cover toward the end of the winter season and are rarely seen during the period of stable cold weather. For the present analysis only the result for the crystal size range $0-3 \mathrm{~mm}$. is considered significant.

The relationship between the hardness defined by the mean logarithm and crystal size is given by:

where $\bar{d}$ is the average crystal size in $\mathrm{mm}$.

$$
\begin{gathered}
\bar{H}=345 \mathrm{e}^{-0.340 \bar{d}} \\
o<\bar{d}<3
\end{gathered}
$$




\section{Discussion OF RESULTS}

The foregoing has brought out the dependence of one strength property of snow, its ultimate strength in compression, on density, temperature, and crystal size. The average relationship can be expressed by:

$$
\begin{array}{cc}
\bar{H} \propto \bar{\rho}^{3.92} \quad \mathrm{e}^{-0.063 T} \mathrm{e}^{-0.340 \bar{d}} \\
\text { where } \\
0.2<\bar{\rho}<0.4 \\
-40<T<0 \\
0<\bar{d}<3 .
\end{array}
$$

Though a dependence was detected in each case, a knowledge of these variables does not completely determine the strength of the snow. This can be seen by referring to Fig. 3 and realizing that variations in temperature and crystal size can account for a spread in hardness values only of the order of a factor of 20 whereas the actual hardness readings have a spread of the order of a factor of 1000 . The results reported here therefore, can only be applied with reservation. To obtain actual strength values, it is necessary to resort to direct measurement.

The factor that probably accounts for the remaining spread in the hardness values and which cannot at the present time be readily evaluated independently, involves the nature of the bonding between the grains. Since the grains, including their relation and bonding to each other, must always tend to be in thermodynamic equilibrium with the environment, the properties of density, grain size and strength must be time-dependent. Therefore, the time-independent relationships normally applied to problems involving the strength of materials, cannot be directly applied to snow.

In problems where it is required to estimate when snow is in the critical state of imminent collapse, an appreciation of the time-dependent factor is arrived at through a knowledge of the past and present meteorological situation. Though this approach is useful where the snow is deforming naturally, it is doubtful whether it would be of much value in engineering problems involving the deformation of snow under applied loads, as the conditions of loading are normally inflexible in relation to meteorological changes. Therefore the engineer in this case may be faced with a large variability in the properties on which he must base his design. The limiting field performance of the designed vehicle or structure may also be subject to this variability. The results shown in Fig. 3 indicate the possible order of magnitude of variability involved.

\section{Conclusion}

The ultimate strength of snow in compression is a highly variable property of the snow cover which cannot be accurately determined except by direct measurement. The mean logarithm of this strength property is dependent on the density of the snow and to a lesser extent on the temperature and crystal size. The factor which is responsible for the indefinite nature of relationships involving the ultimate strength is the bonding between snow grains, a mechanism which is sensitive to thermodynamic forces and is therefore subject to changes with time. Any problems which involve the ultimate strength of snow in compression will be subject to the variability of this property.

\section{ACKNOWLEDGEMENTS}

The author wishes to express his sincere appreciation to all persons associated with the snow survey of Canada and particularly the observers who are responsible for the data on which these results are based. The author also wishes to extend his appreciation to G. Pearl and R. Armour for their assistance in the preparation of this report.

$M S$. received 14 Fanuary 1956 


\title{
R E F E R E N C E S
}

1. Bader, H., and others. Der Schnee und seine Metamorphose. Beiträge zur Geologie der Schweiz. Geotechnische Serie. Hydrologie, Lief. 3, 1939. [English version, Snow and its metamorphism. U.S. Snow, Ice and Permafrost Establishment. Translation No. $14,1954,313$ p.]

2. Nuttall, C. J., and Finelli, J. P. Vehicles in snow; a critical review of the state of the art. Experimental Towing Tank, Stevens Institute of Technology, Hoboken, N.F., U.S.A., Report No. 553, 1954, 66 p.

3. Nakaya, U. Snow crystals, natural and artificial. Cambridge, Mass., Harvard University Press, 1954. 5 ro p.

4. Yosida, Z., and others. Physical studies on deposited snow, I. Thermal properties. Contribution from the Institute of Low Temperature Science, No. 7,1955 , p. 19-74.

5. Quervain, M. de. Schnee als kristallines Aggregat. Experientia, Vol. 1, No. 7, 1945, 17 p. [English version, Snow as a crystalline aggregate. U.S. Snow, Ice and Permafrost Research Establishment. Translation No. $21,1954$.

6. Pearce, D. C., and Gold, L. W. The Canadian snow survey 1947-1950. Canada. National Research Council. Associate Committee on Soil and Snow Mechanics. Technical Memorandum No. 21, 195 I, 39 p.

7. Klein, G. J., Pearce, D. C., and Gold, L. W. Method of measuring the significant characteristics of a snow-cover. Canada. National Research Council. Associate Committee on Soil and Snow Mechanics. Technical Memorandum No. 18 , 1950, 60 p.

8. Butkovitch, T. R. Ultimate strength of ice. U.S. Snow, Ice and Permafrost Research Establishment. Research Paper No. II, 1954, 7 p.

\section{NOTES ON FIRN TEMPERATURES AND ABLATION IN M ACROBERTSON LAND, ANTARCTICA}

\author{
By F. LoEwe
}

(Department of Meteorology, University of Melbourne)

\section{Firn Temperatures}

Firn temperatures on the MacRobertson Land ice cap were observed in December 1954 and January 1955 by Mr. R. Dovers* during a sledging journey from the Australian National Antarctic Research Expedition base station "Mawson” (lat. $67^{\circ} 44^{\prime}$ S., long. $62^{\circ} 54^{\prime}$ E.) southward to lat. $70^{\circ} \mathrm{S}$. These temperatures (Table I) were recorded by spirit thermometers which were lowered into boreholes to a depth of $5 \mathrm{~m}$.

Table I. Firn Temperatures at a Depth of 5 metres on the MacRobertson Land ice cap

\begin{tabular}{|c|c|c|c|c|c|c|c|}
\hline & \multicolumn{3}{|c|}{ Station } & \multirow{2}{*}{$\frac{\begin{array}{l}\text { Lat. } \\
\left(\text { in }^{\circ} \text { S. }\right)\end{array}}{67.9}$} & \multirow{2}{*}{$\frac{\begin{array}{c}\text { Long. } \\
\left(\text { in }^{\circ} \text { E. }\right)\end{array}}{63.5}$} & \multirow{2}{*}{$\begin{array}{c}\begin{array}{c}\text { Height a.s.l. } \\
\text { (in metres) }\end{array} \\
820\end{array}$} & \multirow{2}{*}{$\frac{\begin{array}{c}\text { Temp. } \\
\left(\text { in }^{\circ} \text { C. }\right)\end{array}}{-20.8}$} \\
\hline $\mathrm{D}_{13}$ & . & .. & $\ldots$ & & & & \\
\hline E 6 & . & . & . & $68 \cdot 4$ & 64.0 & 1320 & $-25 \cdot 2$ \\
\hline E ro & . & . & . & $68 \cdot 6$ & $64 \cdot 1$ & I 580 & $-27 \cdot 2$ \\
\hline E I 7 & . & . & . & 69.0 & $64 \cdot 4$ & 1710 & $-28 \cdot 2$ \\
\hline F 5 & $\ldots$ & . & . & $69 \cdot 3$ & $64 \cdot 5$ & 1850 & -30.6 \\
\hline F Io & $\ldots$ & . & . & $69 \cdot 7$ & $64 \cdot 7$ & 2080 & $-31 \cdot 0$ \\
\hline
\end{tabular}

Early in January the near minimum annual temperatures in the firn occur at a depth of $5 \mathrm{~m}$. and are estimated to be about $\mathrm{I}^{\circ} \mathrm{C}$. below the average. In Table II the mean annual temperatures (derived by interpolation) of the upper firn layers of MacRobertson Land are compared with the corresponding ones for Terre Adélie ${ }^{1}$. The mean annual air temperatures are probably slightly lower $^{2}$. In the parts of the MacRobertson Land ice nearer sea level the temperatures are almost identical with those recorded in Terre Adélie, but in the more elevated parts the Terre Adélie temperatures are slightly lower. At a height of $2000 \mathrm{~m}$. the Dronning Maud Land ice cap temperatures ${ }^{3}$ are higher than those recorded in MacRobertson Land. The more southerly position

* Leader of the wintering party at the A.N.A.R.E. base "Mawson," and to whom the writer is indebted for the observations recorded in this paper. 